\title{
Design and implementation speed control system of DC Motor based on PID control and Matlab Simulink
}

\author{
Salman Jasim Hammoodi ${ }^{1}$, Kareem Sayegh Flayyih ${ }^{2}$, Ahmed Refaat Hamad ${ }^{3}$ \\ ${ }^{1}$ Department of Machines Technology, Middle Technical University, Iraq \\ ${ }^{2}$ Department of Electronic Technology, Southern technical University, Iraq \\ ${ }^{3}$ Department of Electrical Technology, Middle Technical University, Iraq
}

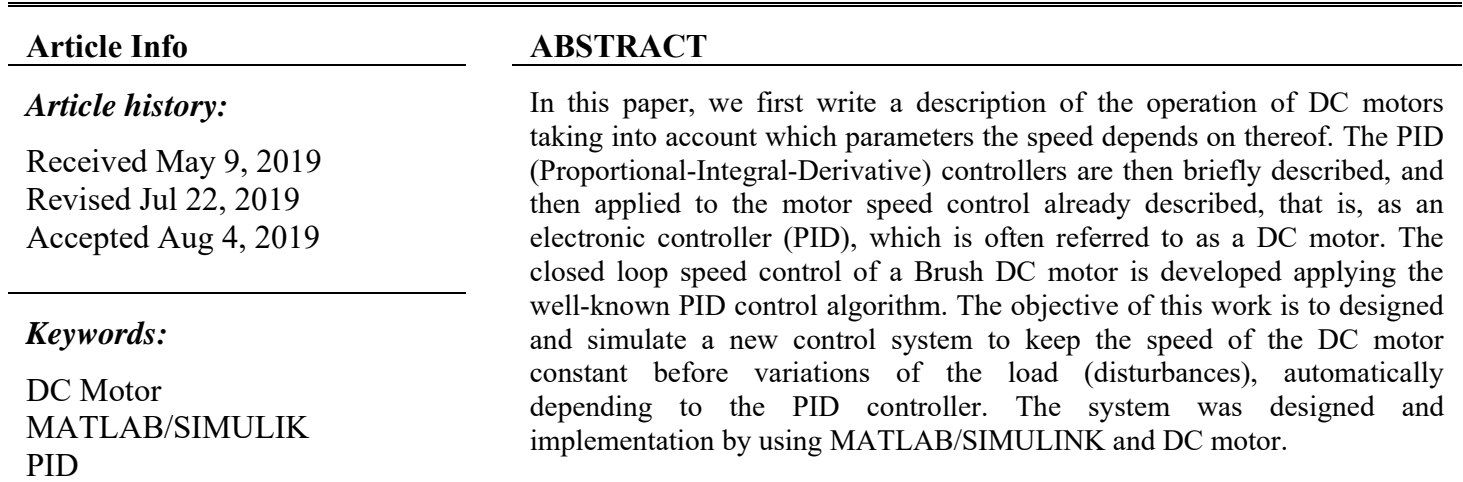

PWM

Speed control

This is an open access article under the CC BY-SA license.

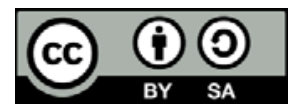

\section{Corresponding Author:}

Salman Hammoodi,

Department of Machines Technology,

Institute of Technology Baghdad, Middle Technical University,

Al-Za'franiya, 10074 Baghdad, Iraq

Email: salmanhammoodi66@gmail.com

\section{INTRODUCTION}

At present, most of the motors in the industry are handled directly from the electrical distribution lines, whether they are DC or AC motors. Because of this, the behaviour of the motor depends on the nature of the load coupled to the axis of the machine [1-5]. In the case of a light load the motor develops a relatively high speed and a low torque because it is the load requirement. On the contrary, if a heavy or difficult to move load is available, the motor will move at a lower speed and deliver more torque as a higher load demands it [4-9].

As can be seen by directly connecting the motor to the AC or DC electrical network, its behaviour is defined and it will remain unchanged for a certain fixed voltage in the power supply line. However, in a large part of the industrial sector, there are processes in which the management of the operating characteristics of said machines is required, which is why parameter control devices such as speed and frequency variations are used. In the case of AC motors, these devices are commonly used and have a relatively low cost, however, when working with DC motors the variable speed drives have an excessively high cost which makes them little accessible to many industries that require its use [6-12].

In this paper to design and implementation speed control system of DC Motor based on PID control and Matlab Simulink, the motor is divided into two main parts the electrical part of the armature and the mechanical part $[11,12]$. The armature is modelled as a circuit with resistance $\mathrm{R}$ connected in series to a conductor $\mathrm{L}$, a source of voltage $\mathrm{V}$ and constant $\mathrm{Kb}$ of force against electromotive in the armature. The 
mechanical part of the motor is the rotor which, when in motion, has a moment of inertia $\mathrm{J}$, a Torque T, a viscous friction coefficient $b$, a position $\theta$ and an angular velocity $b \theta=\omega[4,7,10,11-12]$.

The PID controller is responsible for correcting the error it receives from the difference of the input signal and the output signal of the tachometer, the corrected error enters an amplification stage before entering the plant. In this paper the development of a speed and direction motor for an autonomous race robot is presented. Both controls use the PID control algorithm [13, 15-20].

The paper aims to provide a solution to the difficult access that economic conditions have for these automation technologies, developing an own speed control system for any DC motor that requires it, economically viable and applicable to any type of machine, of easy use and implementation in all types of industrial processes[19-25].

\section{THE BASICS OF DC MOTORS}

The history of the development of the construction of electric machines began in 1831 with the discovery of Faraday's law until the middle of the eighth decade of the last century. The DC motors are machines that convert electrical energy into mechanical energy, causing a rotary movement. There were several reasons for the prolonged popularity of dc motors. One was that DC power systems are common even in cars, trucks and airplanes. When a vehicle has a DC power system, it makes sense to use DC motors. DC motors were also applied when wide variations in speed were required. Before the widespread use of electronic power rectifier inverters, dc motors were not matched in speed control applications. Even if there were no dc power source, the solid-state rectifiers and the trimmer circuits were used to create the necessary power; dc motors were used to provide the desired speed control (induction motors with groups of solid-state controllers are now preferred for most speed control applications.) However, there are still applications where DC motors)[6-9].

The dc motors are driven by a dc power source. Unless otherwise specified, it is assumed that the input voltage is constant, since this assumption simplifies the analysis of the motors and the comparison between the different types of them. There are five types of general purpose DC motors:

- Independent excitation direct current motor.

- Direct current motor in derivation.

- Permanent magnet direct current motor.

- $\quad$ Direct current motor in series.

- Composite direct current motor.

The Figure 1 show the full equivalent circuit of the dc motor. The equivalent circuit in Figure 1 is similar to the generator circuit only the current directions are different. The operation equations are, (1) is present the Armature voltage equation [11-12].

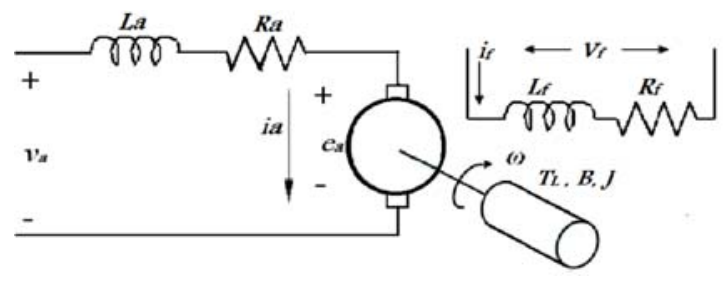

Figure 1. Full equivalent circuit of DC motor

$$
V_{d c}=E_{a m}+I_{a m} R_{a}+V_{b r u s h}
$$

The induced motor voltage and motor speed vs angular frequency of the motor is present in (2). The combination is present in (3) and the output power and torque are present in (4).

$$
\begin{aligned}
& E_{a m}=K_{m} I_{f} \omega \\
& \omega=2 \pi n_{m} \\
& K_{m} I_{f} \omega=E_{a m}=V_{d c}-I_{a m} R_{m} \\
& P_{o u t}=E_{a m} I_{a m}
\end{aligned}
$$




$$
T=\frac{P_{o u t}}{\omega}=K_{m} I_{a m} I_{f}
$$

\section{THE EXPLANATION OF PID CONTROLLER SYSTEM}

\subsection{The control systems}

Automatic control is of vital importance in the world of engineering. In addition to being essential in robotic systems or modern manufacturing processes, among others applications, has become essential in industrial operations such as pressure control, temperature, humidity and viscosity, and flow in the processing industries. Figure 2 shows a generic block diagram of a control system, in the Laplace domain.

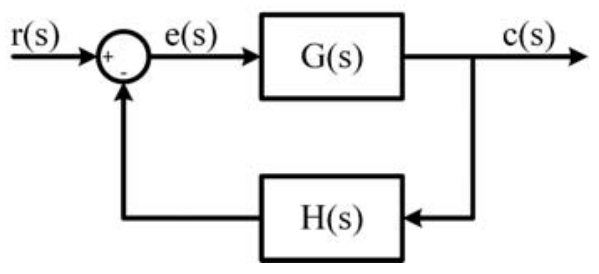

Figure 2. The block diagram of a control system

Typically, the feedback contains a sensor or transducer element that measures a physical parameter, such as speed or temperature, and converts it into a voltage or current.

The basic function of a controller is to compare the real value of the output of a plant $c(t)$, with the reference input $\mathrm{r}(\mathrm{t})$ (desired value), determine the error $\mathrm{e}(\mathrm{t})$, and produce a control signal that will reduce the error to a value close to zero.

Figure 3 present the specifications for a control problem are often given in the time domain, and usually include a certain transient response and an error in state stationary, for a specific entry as is usually a step.

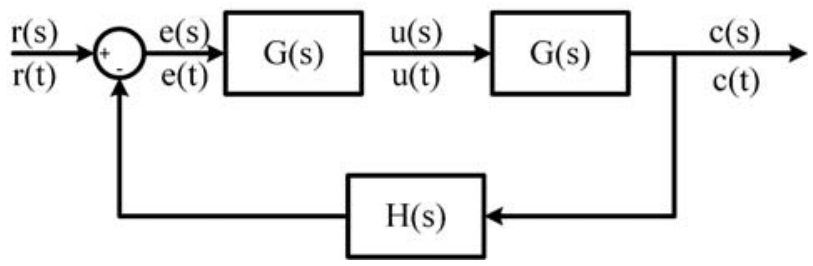

Figure 3. The specifications for a control problem

One way to achieve this is by placing a transfer driver Gc (s), in the control loop, as shown in the Figure 3. The error signal E (s) is the input to the controller, and $U(s)$ is the output of the same and at the same time the input to the plant, and the purpose of the controller is to make the output of the system follow the input. In Figure 4 we observe the different types of response according to the controller that is used.

Design and implementation speed control system of DC Motor based on PID ... (Salman Jasim Hammoodi) 


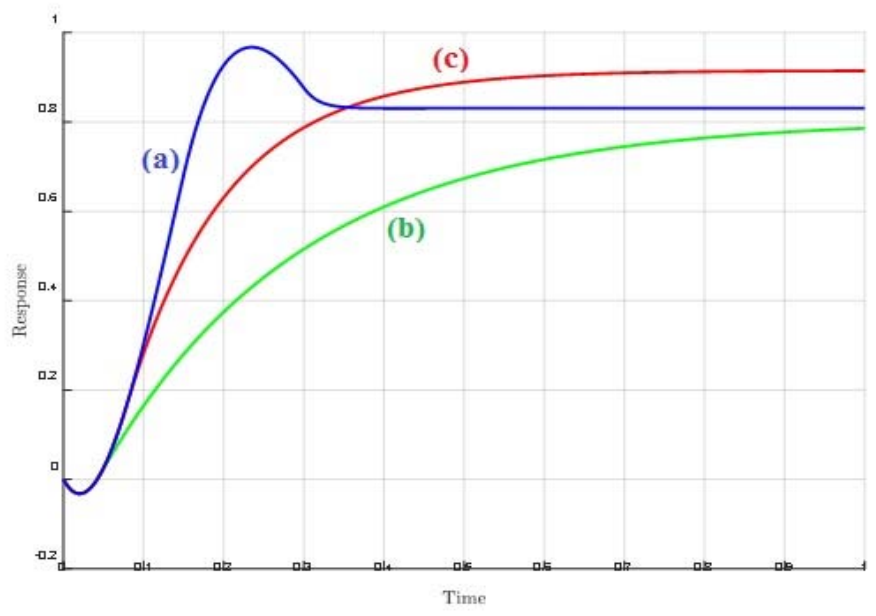

Figure 4. Response to the step of a closed-loop feedback system given by: (a) Controller P (b) Controller PD (c) Controller PID

\subsection{The PID controllers method}

error is changing with respect to time. In this way, the controller can estimate future values of the error signal and compensate accordingly. It should be taken into account that even if the error is constant and the derivative term does not contribute, if it is variant in time this term can be used to reduce the offset called steady-state error. Another problem associated with the PD is that it works like a high-pass filter. Therefore, the PD controller amplifies the high frequency noise, which reduces the stability of the total system.

To eliminate the steady state error, an integral term is added. That term it gives the PID controller the ability to remember the past, also allowing an output non-zero for a null entry. So this controller allows to have a status error stationary equal to zero. In return, the integrator adds a pole in the function of closed loop, with which the stability of the system declines. From the above, the PID is an excellent controller. The transfer function is given in (5)[12-18]:

$$
G_{c}(s)=K_{p}+K_{d} \cdot S+\frac{K_{i}}{S}
$$

It should be clarified that if a mathematical model of the plant can be deduced, it is possible apply several techniques to determine the controller parameters, which comply with the transient and steady state specifications of the closed loop system. However, if the plant is so complicated that you cannot easily obtain your mathematical model, the analytical design model of the PID controller is possible. Then you have to resort to experimental procedures for the design of this type of controller. The process of select the parameters of the controller so that it meets the specifications of operation is known as tuning or tuning the controller. Ziegler and Nichols suggested rules for tuning PID controllers, that is, setting the values of Kp, $\mathrm{Kd}$ and $\mathrm{Ki}[11,16]$.

\subsection{Types of PID controllers}

for PIDs The transfer functions for the different types of PID drivers are[20-25]:

a. PID not interacting or ideal form : is present in (6).

$$
G_{c}(p)=K_{c} \cdot\left(1+\frac{1}{T_{i}}+\frac{1+T_{d} \cdot p}{1+\alpha \cdot T_{d} \cdot p}\right)
$$

b. Interactive PID or series form : is present in (7).

$$
G_{c} \cdot(p)=K_{c} \cdot\left(1+\frac{1}{K_{i} \cdot p}\right) \cdot\left(\frac{1+T_{d}}{1+\alpha \cdot T_{d} \cdot p}\right)
$$

c. PID parallel form : is present in (8). 


$$
G_{c}(p)=K_{p}+\frac{K_{i}}{p}+\frac{K_{d} \cdot p}{1+\alpha \cdot T_{d} \cdot p}
$$

d. PID industrial form : is present in (9).

$$
u(t)=K_{c} \cdot\left(1+\frac{1}{T_{d} \cdot p}\right) \cdot\left(r(t)-\frac{1+T_{d} \cdot p}{1+\alpha \cdot T_{d} \cdot p} \cdot y(t)\right)
$$

\section{SIMULATION RESULTS AND DESCTIONS}

Figure 5 shows the final MATLAB/SIMULINK speed control circuit separately excited dc motor using chopper transistor circuit. MATLAB/SIMULINK toolbox is used in this paper to model the full system, it consists of DC motor fed by a DC source voltage through a chopper transistor circuit. A single of GTO-1 thyristor with its full control circuit and a free wheeling diode form the chopper circuit. The GTO-1 is a switch modeled. The switch block model has three terminals: the middle terminal is a controls which of the two other terminals is routed to the output. The control input signal is one, DC V is leading to the output voltage, on the other hand, the control input singals is zero, a zero will be leading to the output.

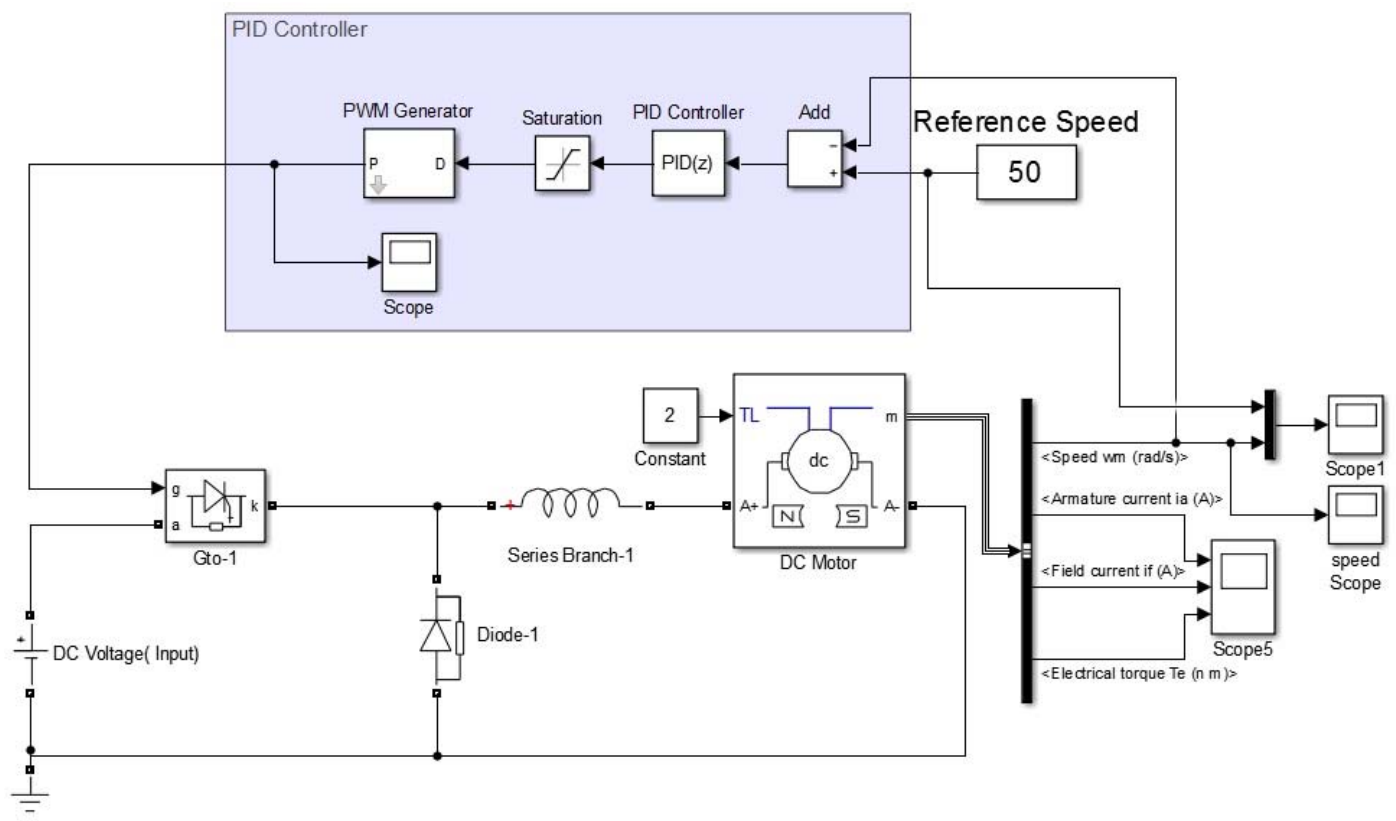

Figure 5. The final simulation circuit of the speed control motor based on PID control

The DC motor drives system with a mechanical load characterized by inertia $(J)$, friction coefficient (B), and torq of the load (TL). The control circuit of the DC motor system consists of a speed control loop. A proportional-integral-Drivetive (PID) controlled the speed of the control loop senses the actual speed of the DC motor, and compares the mesurring speed with the reference speed (constant value) to determine the reference armature current will be required by the DC motor. One may notice that any difference in actual speed is a measure of the current of the motor required by the engine.

The simulation results of the full system are present on Figure 6 to Figure 9. Figure 6 present the simulation results of rated speed (wr) related to the reference speed, in this figure we can see the fast response of the PID control system of the system.

Design and implementation speed control system of DC Motor based on PID ... (Salman Jasim Hammoodi) 


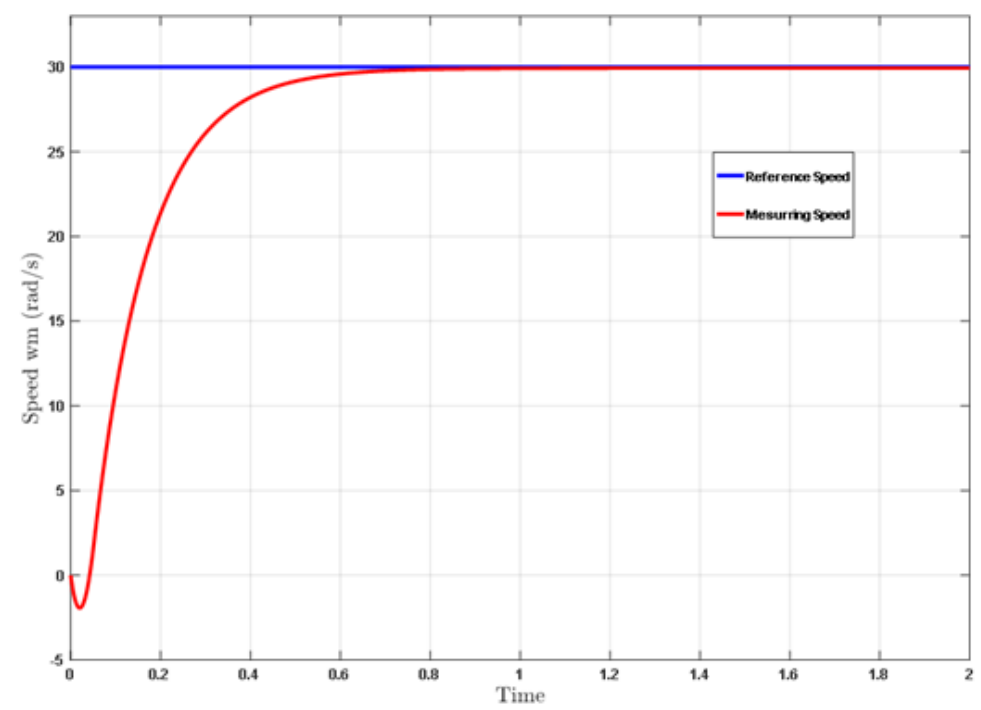

Figure 6. Simulation results of rated speed (wr) related to the reference speed

The load torque (TL) in Figure 7 and the armature current (A) of the DC motoe is presented in the Figure 8 of the DC motor is presented the same fast response of the PID control system. Finaly the PWM signals of the thyristor (GTO-1) is presented in the Figure 9.

Note: The parameter of the PID are $(\mathrm{P}=4, \mathrm{I}=0.01$ and $\mathrm{D}=0.5$.

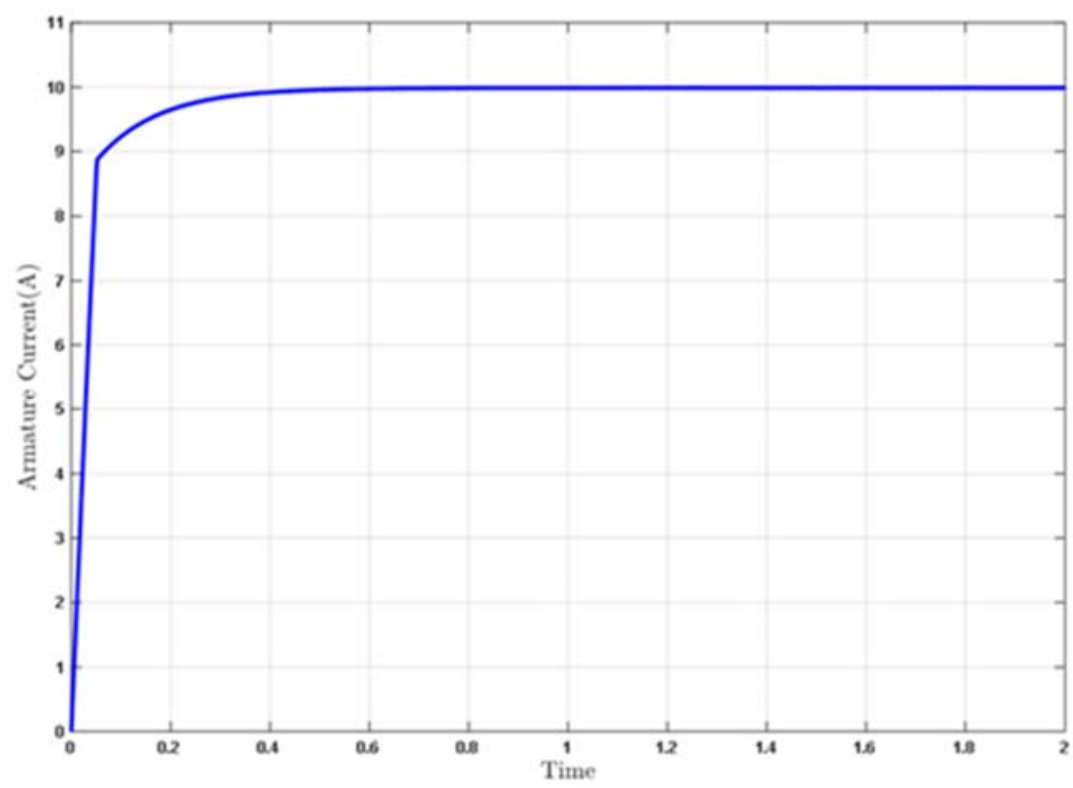

Figure 7. The load torque (TL) of the DC motoe 


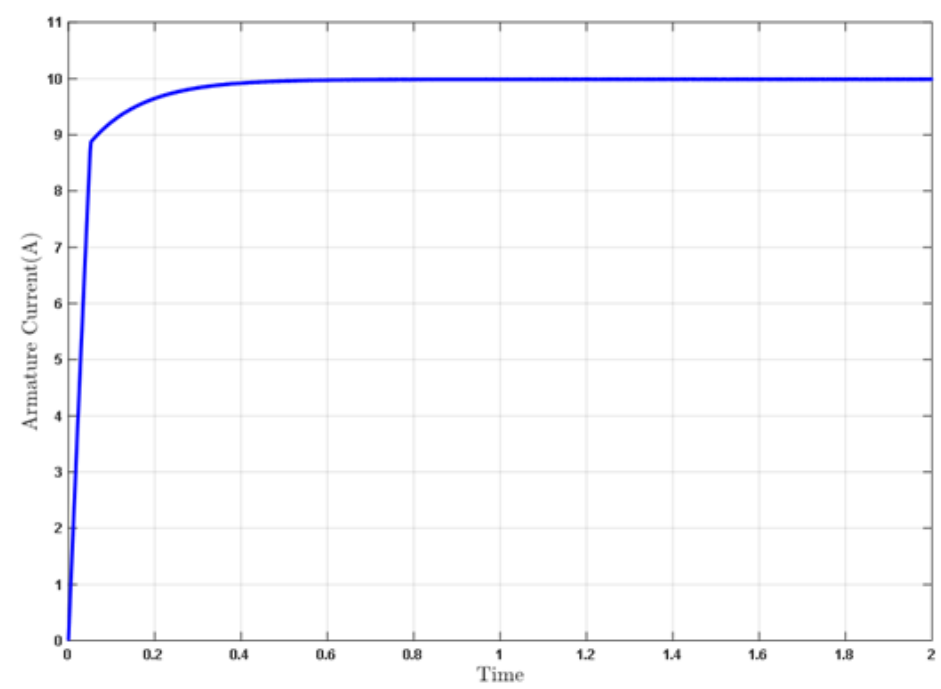

Figure 8. The armature current (A) of the DC motoe

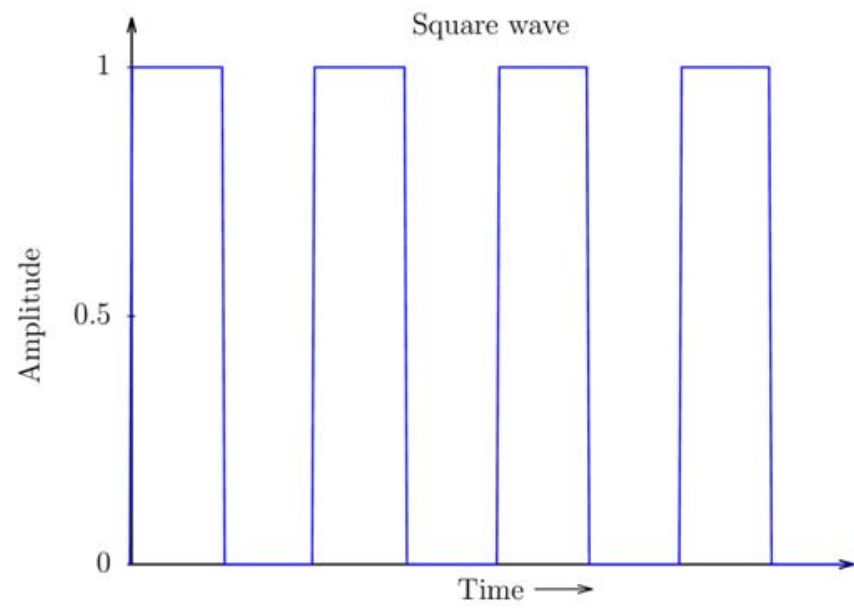

Figure 9. The PWM signals of the thyristor (GTO-1)

\section{CONCLUSION}

The first point discussed in this work was the description of the operation of a DC motor, where the different aspects related to its operation were analysed, and the parameters that influence the speed control of them. Then, made the operation of the PID controllers system, and their application to the control of the speed of a DC motor. It is important to consider here that the effect on the dynamic behaviour of a control loop is directly related to the type of controller used, PID in our specific case, and its operation, either as a servomechanism or as a regulatory system. But it must also be taken into account that the equations used by the manufacturers to carry out their PID controllers are not all the same.

The differences that exist between the equations used by the manufacturers to represent the PID algorithm in their loop controllers, direct digital control programs and other equipment, make it indispensable to know in order to be able to calculate the required parameters thereof in an appropriate manner and achieve the desired dynamic behaviour of the control loop. The foregoing is fundamentally important when replacing one controller with another, especially if the new one is from another manufacturer.

The results that have been presented and the methodology that has been proposed represent an important contribution in the field of experimental modelling of systems for obtaining models of the dynamics of unknown systems.

Design and implementation speed control system of DC Motor based on PID ... (Salman Jasim Hammoodi) 


\section{REFERENCES}

[1] A. J. Humaidi and I. Kasim Ibraheem, "Speed Control of Permanent Magnet DC Motor with Friction and Measurement Noise Using Novel Nonlinear Extended State Observer-Based Anti-Disturbance Control," Energies, vol. 12, no. 9, p. 1651, 2019.

[2] X. Yao, J. Zhao, G. Lu, H. Lin, and J. Wang, "Commutation Error Compensation Strategy for Sensorless Brushless DC Motors," Energies, vol. 12, no. 2, p. 203, 2019.

[3] J. Hong, S. Wang, Y. Sun, and H. Cao, "An effective method with copper ring for vibration reduction in permanent magnet brush DC motors," IEEE Trans. Magn., vol. 54, no. 11, pp. 1-5, 2018.

[4] L. Li and D. Jia, "Research on Air conditioning system of subway station based on fuzzy PID control," Proc. 2017 4th Int. Conf. Inf. Sci. Control Eng. ICISCE 2017, pp. 1131-1134, 2017.

[5] E. Guerrero, J. Linares, E. Guzmán, H. Sira, G. Guerrero, and A. Martínez, "DC Motor Speed Control through Parallel DC/DC Buck Converters," IEEE Lat. Am. Trans., vol. 15, no. 5, 2017.

[6] P. Alaeinovin and J. Jatskevich, "Filtering of hall-sensor signals for improved operation of brushless DC motors," IEEE Trans. Energy Convers., vol. 27, no. 2, pp. 547-549, 2012.

[7] X. Changbo, L. Congcong, B. Zhenfu, and Z. Chengjin, "PID self-tuning immune fuzzy control of steam temperature control system in fossil-fired power plant," Proc. World Congr. Intell. Control Autom., vol. 1, pp. 3973-3977, 2006.

[8] N. Kasa and H. Watanabe, "A mechanical sensorless control system for salient-pole brushless DC motor with autocalibration of estimated position angles," IEEE Trans. Ind. Electron., vol. 47, no. 2, pp. 389-395, 2000.

[9] Y. Mandel and G. Weiss, "Reduction of torque ripple in brushless DC motor drives," IFAC Proc., vol. 6, no. 1, pp. 84-89, 2009.

[10] I. Alhamrouni, M. A. Hairullah, N. S. Omar, M. Salem, A. Jusoh, and T. Sutikno, "Modelling and design of PID controller for voltage control of AC hybrid micro-grid," International Journal of Power Electronics and Drive System (IJPEDS), vol. 10, no. 1, pp. 151-159, 2019.

[11] M. A. Ibrahim, A. K. Mahmood, and N. S. Sultan, "Optimal PID controller of a brushless DC motor using genetic algorithm," International Journal of Power Electronics and Drive System (IJPEDS), vol. 10, no. 2, pp. 822-830, 2019.

[12] N. N. Baharudin and S. M. Ayob, "Brushless DC motor speed control using single input fuzzy PI controller," International Journal of Power Electronics and Drive System (IJPEDS), vol. 9, no. 4, pp. 1952-1966, 2018.

[13] Y. Tarmizi, A. Jidin, K. A. Karim, and T. Sutikno, "A simple constant switching frequency of direct torque control of brushless DC motor," International Journal of Power Electronics and Drive System (IJPEDS), vol. 10, no. 1, pp. $10-18,2019$.

[14] M. Dasari, A. Srinivasula Reddy, and M. Vijaya Kumar, "GA-ANFIS PID compensated model reference adaptive control for BLDC motor," International Journal of Power Electronics and Drive System (IJPEDS), vol. 10, no. 1, pp. 265-276, 2019.

[15] Mohannad Jabbar Mnati, "Position Control for flexible Joint Maipulator using Artificaial Neutral Network", University of Technology, Department Of Electrical \& Electrionics Engineering, Baghdad, Iraq, 2005.

[16] P. Bhaskara Prasad, M. Padma Lalitha, and B. Sarvesh, "Fractional order PID controlled cascaded re-boost seven level inverter fed induction motor system with enhanced response," International Journal of Power Electronics and Drive System (IJPEDS), vol. 9, no. 4, pp. 1784-1791, 2018.

[17] R. Meena Devi and L. Premalatha, "Soft computing technique of bridgeless SEPIC converter for PMBLDC motor drive," International Journal of Power Electronics and Drive System (IJPEDS), vol. 9, no. 4, pp. 1503-1509, 2018.

[18] A. Rincón, F. Angulo, and F. Hoyos, "Controlling a DC Motor through Lypaunov-like Functions and SAB Technique," International Journal of Electrical and Computer Engineering (IJECE), vol. 8, no. 4, p. 2180, 2019.

[19] M. J. Mnati, D. V. Bozalakov, and A. Van den Bossche, "PID Control of a Three Phase Photovoltaic Inverter Tied to a Grid Based on a 120-Degree Bus Clamp PWM," IFAC-PapersOnLine, vol. 51, no. 4, pp. 388-393, 2018.

[20] A. Faruq, M. F. N. Shah, and S. S. Abdullah, "Multi-objective optimization of PID controller using pareto-based surrogate modeling algorithm for MIMO evaporator system," International Journal of Electrical and Computer Engineering (IJECE), vol. 8, no. 1, pp. 556-565, 2018.

[21] A. Prayitno, V. Indrawati, and I. I. Trusulaw, "Fuzzy gain scheduling PID control for position of the AR. Drone," International Journal of Electrical and Computer Engineering (IJECE), vol. 8, no. 4, pp. 1939-1946, 2018.

[22] H. Sun, M. J. Mnati, M. Nabil Ibrahim, and A. Van Den Bossche, "A Tuning Method for the Derivative Filter in PID Controller with Delay Time,” Proc. 2018 9th Int. Conf. Mech. Aerosp. Eng. ICMAE 2018, pp. 574-578, 2018.

[23] H. Sun, M. N. Ibrahim, M. Jabbar Mnati, and A. Van Den Bossche, "A Tuning Method for PI Controller for an Integrating System with Time Delay,” Proc. 2018 9th Int. Conf. Mech. Aerosp. Eng. ICMAE 2018, pp. 410-414, 2018.

[24] M. Yaich and M. Ghariani, "A novel technique for tuning PI-controller in switched reluctance motor drive for transportation systems," International Journal of Electrical and Computer Engineering (IJECE), vol. 8, no. 6, pp. 4272-4281, 2018.

[25] M. A. Shamseldin, M. Sallam, A. M. Bassiuny, and A. M. Abdel Ghany, "A novel self-tuning fractional order PID control based on optimal model reference adaptive system," International Journal of Power Electronics and Drive System (IJPEDS), vol. 10, no. 1, pp. 230-241, 2018.

Int J Pow Elec \& Dri Syst Vol. 11, No. 1, Mar 2020 : $127-134$ 